\title{
PHASE RESOLVED ANALYSIS OF FLAME STRUCTURE IN LEAN PREMIXED SWIRL FLAMES OF A FUEL STAGED GAS TURBINE MODEL COMBUSTOR
}

\author{
J. D. Gounder, ${ }^{1}$ I. Boxx, ${ }^{1}$ P. Kutne, ${ }^{1}$ S. Wysocki, ${ }^{2}$ \\ and F. Biagioli ${ }^{2}$ \\ ${ }^{1}$ German Aerospace Center, Institute for Combustion Diagnostics, Stuttgart, \\ Germany \\ ${ }^{2}$ ALSTOM (Switzerland) Ltd, Baden, Switzerland
}

A scaled model of a gas turbine (GT) burner with coaxially mounted swirlers has been used to study the effects of fuel staging on the behavior of lean premixed methane air flames. Lean flames are known to be susceptible to instabilities that can lead to unsteady operation, flame extinction, and thermo-acoustic oscillations. High speed $(10 \mathrm{kHz})$ laser and optical diagnostic techniques have been used to investigate the fuel staging effect on the mechanisms involved in such instabilities. Methane air flames at atmospheric pressure have been investigated at a constant thermal power of $58 \mathrm{~kW}$. The global equivalence ratio was kept constant, while the fuel staging was varied. The bulk flow velocity at the exit plane was kept constant at $20 \mathrm{~m} / \mathrm{s}$. Simultaneous high speed $\mathrm{OH} \mathrm{PLIF}, \mathrm{OH}^{*} \mathrm{CL}$, and acoustic measurements were performed at $\mathrm{kHz}$ repetition rate to characterize the flames and determine the operability limits of the combustor. The characterization measurements reveal significant changes in flame shape for various staging ratios as well as onset of self-excited thermo-acoustics in flames with more than 55\% fuel injection in the outer swirler. The phase resolved analysis of the $\mathrm{OH}^{*} \mathrm{CL}$ revealed pulsation in the heat release due to acoustics in flames with higher percentage of fuel in the outer swirler. Comparison of the pressure oscillation in the combustion chamber with the heat release yielded a clear picture regarding the feedback mechanism that sustains the self-excited thermo-acoustic pulsations. The variation of local equivalence ratio of the mixture seems to be the driving force that initiates the onset of acoustics pulsations.

Keywords: Gas turbine model combustor; kHz OH-PLIF; Staged combustion; Swirl flame

\section{INTRODUCTION}

Turbulent swirl flames are an integral part of gas turbine combustors for power generation. While the combustion process provides heat for power generation, it also emits by-products (NOx, $\mathrm{CO}, \mathrm{CO}_{2}, \mathrm{UHC}$ ) which are harmful. This has led to stringent rules governing the design of power generation gas turbines (Lefebvre and Ballal, 2010). In order to meet the low emission requirements, research is aimed at understanding the combustion

Received 15 May 2013; revised 29 October 2013; accepted 19 November 2013.

Published as part of the Eighth Mediterranean Combustion Symposium Special Issue with Guest Editors Nevin Selçuk, Federico Beretta, Mohy S. Mansour, and Andrea d'Anna.

Address correspondence to J. D. Gounder, German Aerospace Center, Institute for Combustion Diagnostics, Pfaffenwaldring 38-40, 70569 Stuttgart, Germany. E-mail: James.Gounder@dlr.de

Color versions of one or more of the figures in the article can be found online at www.tandfonline.com/gcst. 
processes occurring in gas turbine (GT) combustors as shown by following groups (Adachi et al., 2007; Chockalingam et al., 2011; Hayashi et al., 2005; Kolb et al., 1988; Meier et al., 2010; Sadanandan et al., 2008; Zajadatz et al., 2007). The low emissions have been achieved with lean premixed combustion, but the drawback of it is the resulting strong thermo-acoustic instabilities. It becomes a balancing act to achieve low emissions while trying to avoid strong instabilities that could lead to mechanical failure.

The physical constraints and lack of optical access to the gas turbine combustor makes it difficult to perform sophisticated laser and optical diagnostic measurements while the gas turbine is in operation. The solution to this has been experiments tailored for laboratories using scaled models of gas turbine burners. Detailed studies have been conducted using low repetition rate (Duan et al., 2005; Meier et al., 2007, 2010; Sadanandan et al., 2008, 2009; Stöhr et al., 2011a, 2011b), as well as high speed (kHz) laser diagnostic measurements (Boxx et al., 2010, 2012; Moeck et al., 2012; Steinberg et al., 2010; Stöhr et al., 2011a, 2011b) to understand turbulence chemistry interactions, aerodynamics, and thermo-acoustics. The availability of good experimental data has led to advancement and improvement of numerical studies of gas turbine combustion (Geigle et al., 2006; Grinstein and Fureby, 2005; Jones et al., 2012; Martin et al., 2006; Nogenmyr et al., 2009).

A number of studies have looked at staging effects on NOx emissions (Adachi et al., 2007; Chockalingam et al., 2011; Hayashi et al., 2005; Johnson et al., 2005; Littlejohn and Cheng, 2007; Zajadatz et al., 2007), while others have investigated the thermo-acoustic instabilities in various configurations of staged burners (Barbosa et al., 2009; Fritsche et al., 2007; Martin et al., 2006; Therkelsen et al., 2013). In this study, a conceptual design of an industrial GT burner is used to investigate the effects of fuel staging and running conditions with enhanced thermo-acoustic pulsations. This work looks into future development and improvement of GT burners through evolution of existing burners into new concepts that could provide better understanding of the physics behind the complex processes that are present in a GT combustor.

Laser and optical diagnostics techniques at $\mathrm{kHz}$ repetition rate are used to perform measurements in a number of flames where fuel staging varied the fuel flow rate to the different swirler stages. High-speed $(10 \mathrm{kHz})$ planar laser induced fluorescence (PLIF) of $\mathrm{OH}$ and $\mathrm{OH}^{*}$ chemiluminescence (CL) and acoustic measurements were performed to investigate the effect of fuel staging on lean premixed flame behavior. Flame characterization measurements presented in (Gounder et al., 2013) are analyzed using phase resolved analysis.

\section{EXPERIMENTAL SETUP}

The setup of the burner and laser diagnostics techniques used are presented in Figure 1. A detailed description of the experimental setup is presented by Gounder et al. (2013). All experiments were conducted using a conceptual burner designed for gas turbine application. The burner consists of two coaxially mounted swirlers. Each swirler has its own fuel feed line, which allows for fixed percentages of the total fuel flow to be fed to them. Figure 1a shows a schematic of the combustor assembly where the burner is mounted in a housing with a plenum. Preheated air is fed into the plenum before separating and passing through the swirlers. Approximately $35 \%$ of the total air flow passes through the inner swirler. Fuel is injected into the air stream through evenly spaced holes at the base of the swirlers. The injection of fuel at high momentum into the air flow allows for initial fuel 

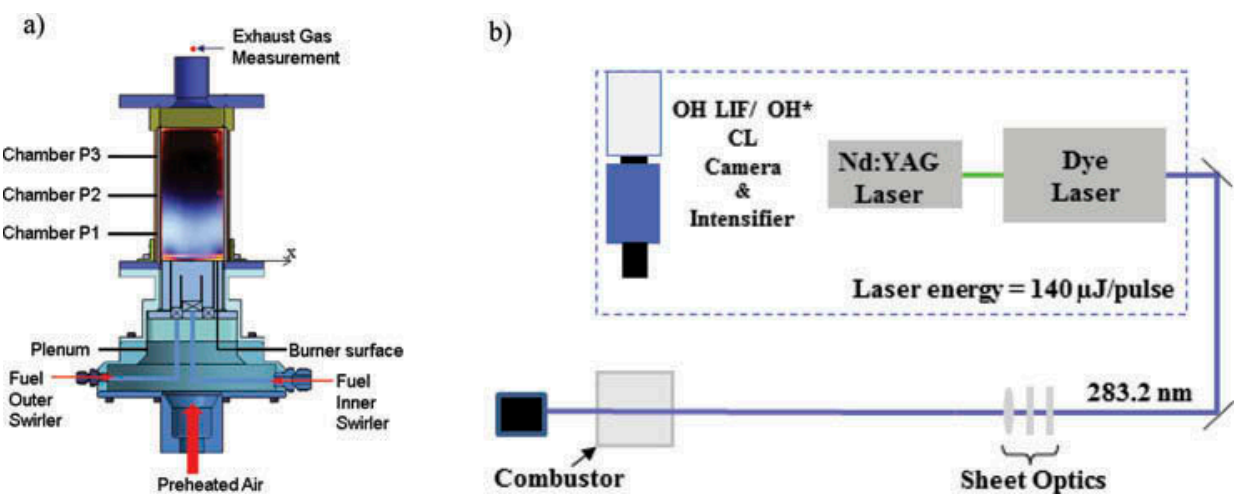

Figure 1 (a) Cross-sectioned view of the burner and optical combustion chamber assembly. (b) Layout of simultaneous $10 \mathrm{kHz}$ OH PLIF and $\mathrm{OH}^{*}$ chemiluminescence setup.

air mixing in each swirler. Further premixing between fuel/air mixtures originating from the individual swirler stage occurs downstream of exit plane of the inner swirler mixing tube before entering the combustion chamber. The air and fuel flows to the outer and the inner swirlers were metered with electromechanical flow controllers (Bronkhorst for air and Brooks for fuel) and monitored using calibration standard Coriolis mass flow meters (Siemens Sitrans F C) with an uncertainty of $1.5 \%$.

The optically accessible combustion chamber consists of large quartz windows of thickness $2.5 \mathrm{~mm}$ held in the corner by an Inconel alloy post. The enclosed cross-section is $85 \times 85 \mathrm{~mm}$, and the length of the chamber is $203 \mathrm{~mm}$. Quartz windows of height $176.5 \mathrm{~mm}$ provided unobstructed optical access to nearly the entire flame zone. A fraction of the preheated air is used for impingement cooling of the burner front surface. The exit of the chamber is a conical contraction leading to a short central pipe with a diameter of $40 \mathrm{~mm}$. As shown in Figure 1a, the combustor assembly was equipped with multiple ports for microphone probes. Five probes (Bruel \& Kjaer, Type 4939) were used for this study, two of which were mounted on the outer wall of the plenum housing, where one probe was used for measuring the pressure signal in the plenum and the other was connected to a tube leading to the burner surface. Three probes were mounted equidistantly from each other on one of the posts. The position of the first probe is $37 \mathrm{~mm}$ from the burner exit plane, and the distance between each probe is $50 \mathrm{~mm}$. The signals are recorded simultaneously using a multichannel A/D converter with a sampling rate of $100 \mathrm{kHz}$. The microphones have been sampled simultaneously with the gate monitor signals of the image intensifier in order to directly identify the phase of the thermo-acoustic cycle for each $\mathrm{OH}^{*} \mathrm{CL}$ image.

Figure $1 \mathrm{~b}$ shows the layout of the laser and camera setup for OH PLIF and OH* CL imaging. These measurements were performed at a repetition rate of $10 \mathrm{kHz}$. The OH PLIF system consisted of a frequency doubled dye laser and an intensified CMOS camera. The dye laser (Sirah Credo) using Rhodamine 6G dye dissolved in ethanol was pumped with a frequency doubled, Q-switched, diode pumped solid state Nd:YAG laser (Edgewave IS$811 \mathrm{E})$. At $10 \mathrm{kHz}$, the pump laser delivered $3.8 \mathrm{~mJ} /$ pulse at $532 \mathrm{~nm}$ with an $8.5 \mathrm{~ns}$ pulse duration. The output of the dye laser was frequency doubled to excite the $\mathrm{Q}_{1}(7)$ line of the A-X(1-0) transition of $\mathrm{OH}$ at $283.2 \mathrm{~nm}$. The output energy of the dye laser beam was 138 $\mu \mathrm{J} /$ pulse. The dye laser beam was formed into a sheet of $43 \mathrm{~mm}$ height using two fused silica lenses $\left(f_{1}=-25 \mathrm{~mm}\right.$ and $\left.f_{2}=250 \mathrm{~mm}\right)$ in a cylindrical telescope configuration 
and focused to a waist of approximately $0.4 \mathrm{~mm}$ using a third cylindrical lens $\left(\mathrm{f}_{3}=\right.$ $500 \mathrm{~mm})$.

Fluorescence signal was acquired with a CMOS camera (Lavision HSS8), external two stage, lens-coupled intensifier (Lavision HS-IRO) and a fast Cerso $45 \mathrm{~mm}$, $\mathrm{f} / 1.8$ lens. Background luminosity was reduced using a $500 \mathrm{~ns}$ intensifier gate, and elastic scattering from PIV particles (PIV measurements are not presented in this article) at $283 \mathrm{~nm}$ was blocked using a high transmission bandpass interference filter with center wavelength at $310 \mathrm{~nm}$ and a $1 \mathrm{~mm}$ thick color glass filter (WG295 Schott glass). The $\mathrm{OH}$ images are corrected for the mean laser sheet intensity profile, which was obtained using 1000 images of the laser induced fluorescence from a uniform acetone vapor that was doped into the combustion chamber. The $\mathrm{OH}^{*} \mathrm{CL}$ images were collected using the $\mathrm{OH}$ PLIF camera with the laser switched off and the intensifier gate time increase to $40 \mu \mathrm{s}$.

\section{BURNER CHARACTERIZATION AND INITIAL CONDITIONS}

The present work is the continuation of our study (Gounder et al., 2013) of fuel staging effect on the flame structure, stabilization mechanism, and thermo-acoustic instabilities in methane air flames at atmospheric pressure. A detailed description of the operability limit of the burner has been presented by Gounder et al. (2013); therefore a summarized version of the burner characterization and initial conditions are provided here. The bulk exit plane velocity for all flames investigated was kept constant at $20 \mathrm{~m} / \mathrm{s}$. Preheated air at $523 \mathrm{~K}$ is fed from the plenum into the swirlers. The effect of fuel staging was investigated by varying the fuel flow rate to the inner (IS) and outer (OS) swirler while keeping the global equivalence ratio $\left(\Phi_{\mathrm{G}}\right)$ constant. During the flame characterization phase, the burner was operated at constant $\Phi_{\mathrm{G}}$ and thermal power of 0.68 and $58 \mathrm{~kW}$, respectively. At this condition, exhaust gas, OH PLIF, and simultaneous $\mathrm{OH}^{*} \mathrm{CL}$ and acoustic measurements were performed to monitor flame structure and determine optimum staging ratio. The staging ratio is defined as ratio of $\Phi$ of mixture from inner swirler (IS) to the outer swirler (OS), and this is presented in Table 1 . All $\Phi$ values presented in Table 1 were calculated using the mass flow rates measured using Coriolis mass flow meters. The staging ratio is varied through the percentage of fuel injected in each swirler stage. The flames that were investigated in this study have been labeled as follows: Flame number $1 /$ number 2 , where number 1 is the percentage of fuel in the outer swirler and number 2 is the percentage of fuel in the inner swirler (for example Flame $40 / 60=40 \%$ fuel in the outer swirler and $60 \%$ in the inner swirler), and this nomenclature will be used for the rest of the discussion.

For a fixed bulk velocity and global $\Phi$, a number of flames with varying staging ratios have been investigated. Stable flame operation was archived between staging ratio 5.2 and 1.2, as shown in Table 1. Beyond the staging ratio of 1.2, strong thermo-acoustics caused the combustion chamber windows to break. The first flame at a staging ratio of 5.2 is stabilized by the richer mixture from the inner swirler, and as the staging is varied, the stoichiometry of both stages approaches the global equivalence ratio. Out of the six staging ratios presented in Table 1 , an optimum ratio was determined based on the minimum $\mathrm{CO}$ and NOx measured in the exhaust of the respective flames. The optimum staging ratio for this burner configuration was 1.8 (Flame 55/45) as shown by Gounder et al. (2013). 
Table 1 Variation of equivalence ratio of mixture in outer swirler stage ( $\left.\Phi_{\mathrm{OS}}\right)$ and the staging ratio $\left(\Phi_{\mathrm{IS}} / \Phi_{\mathrm{OS}}\right)$ [Results from flames with staging ratio 3.3, 1.8, and 1.2 (bold text) are presented in this article]

\begin{tabular}{lccc}
\hline Label & $\Phi_{\text {global }}$ & $\Phi_{\mathrm{OS}}$ & $\Phi_{\mathrm{IS}} / \Phi_{\mathrm{OS}}$ \\
\hline Flame 30/70 & 0.70 & 0.30 & 5.2 \\
Flame 40/60 & $\mathbf{0 . 6 9}$ & $\mathbf{0 . 4 0}$ & $\mathbf{3 . 3}$ \\
Flame 50/50 & 0.70 & 0.51 & 2.2 \\
Flame 55/45 & $\mathbf{0 . 6 8}$ & $\mathbf{0 . 5 4}$ & $\mathbf{1 . 8}$ \\
Flame 60/40 & 0.68 & 0.59 & 1.5 \\
Flame 65/35 & $\mathbf{0 . 6 8}$ & $\mathbf{0 . 6 4}$ & $\mathbf{1 . 2}$ \\
\hline
\end{tabular}

\section{Pressure Fluctuations and Phase Angles}

The pressure fluctuations measured in Flame 65/35 using the microphone probes are shown in Figure 2. The power density spectra of the signal from the plenum and the middle probe on the chamber (Chamber P2) are shown in Figure 3b. The assignment of the phase angles to the pressure fluctuations was conducted as described by Giezendanner et al. (2003). The minimum and maximum pressure in the plenum corresponds to $0^{\circ}$ and $180^{\circ}$ phase angles. The zero pressure points correspond to $90^{\circ}$ and $270^{\circ}$, respectively, and the midway points are represented by $45^{\circ}$ increments from previous phase angle hence resulting in phase 8 at $315^{\circ}$. The pressure signal from the middle microphone probe (Chamber P2) is used for representing the pressure fluctuation in the chamber as it lies in between the signals from the other two probes. The plenum pressure signal lags behind the pressure measured in the combustion by $135^{\circ}$. This could be due to the time required for the pressure wave to travel from the chamber to the position of the microphone probe in the plenum. The phase angle for each $\mathrm{OH}^{*} \mathrm{CL}$ measurement is calculated from the location of the trigger signal of the $\mathrm{OH}$ intensifier with respect to the plenum pressure signal. All images are then assigned into $45^{\circ}$ bins of the 8 phase angles $\left(0^{\circ} \pm 22.5^{\circ}, 45^{\circ} \pm 22.5^{\circ}, \ldots, 315^{\circ} \pm 22.5^{\circ}\right)$, from which averages were then calculated.

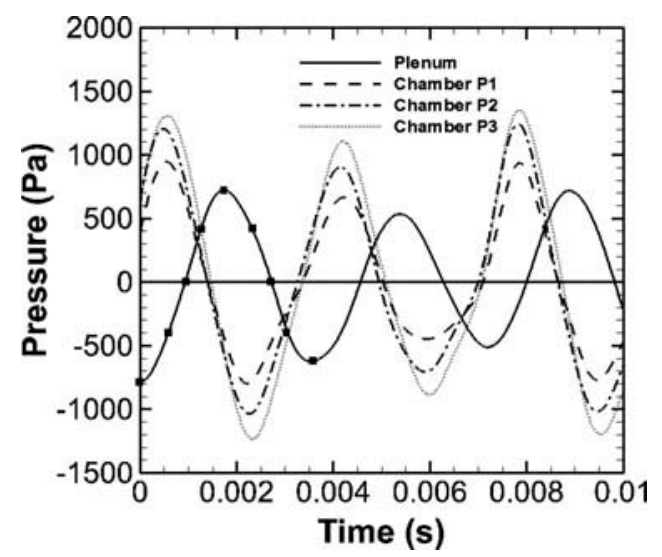

Figure 2 Pressure signals measured in the plenum and combustion chamber for Flame 65/35. The dots represent the eight assigned phase angles from $0^{\circ}$ until $315^{\circ}$ with $45^{\circ}$ intervals. 


\section{RESULTS AND DISCUSSION}

\section{Flame Characterization}

Electronically excited $\mathrm{OH}\left(\mathrm{OH}^{*}\right)$ is formed by the flame reactions in the regions of the highest heat release rates, and has been shown to be a good marker of the flame zone (Haber and Vandsburger, 2003; Hardalupas and Orain, 2004). The shape of the flame and position of the heat release zone can be determined from $\mathrm{OH}^{*} \mathrm{CL}$ images. Figure $3 \mathrm{a}$ shows the mean $\mathrm{OH}^{*} \mathrm{CL}$ images of three flames with staging ratios 3.3,1.8, and 1.2, respectively. The $\mathrm{OH}$ intensity of flames decreases as the staging ratio is varied from 3.3 to 1.2. The flame base for Flame $40 / 60\left(\Phi_{\mathrm{IS}} / \Phi_{\mathrm{OS}}=3.3\right)$ is upstream of the burner exit plane. As more fuel is fed into the outer swirler, the flame base slowly moves out and stabilizes at the exit

a)
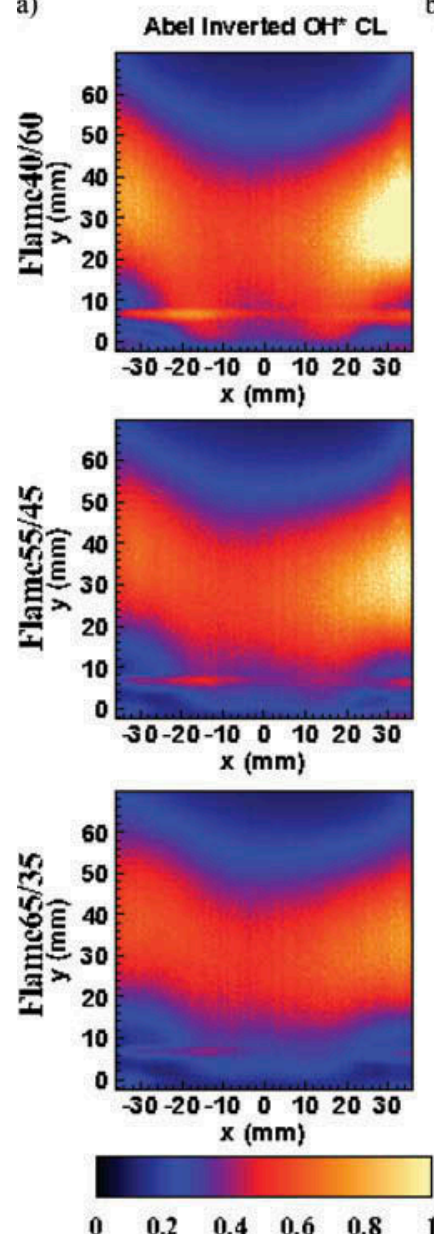

$\mathrm{OH}^{*}$ Intensity (a.u) b)
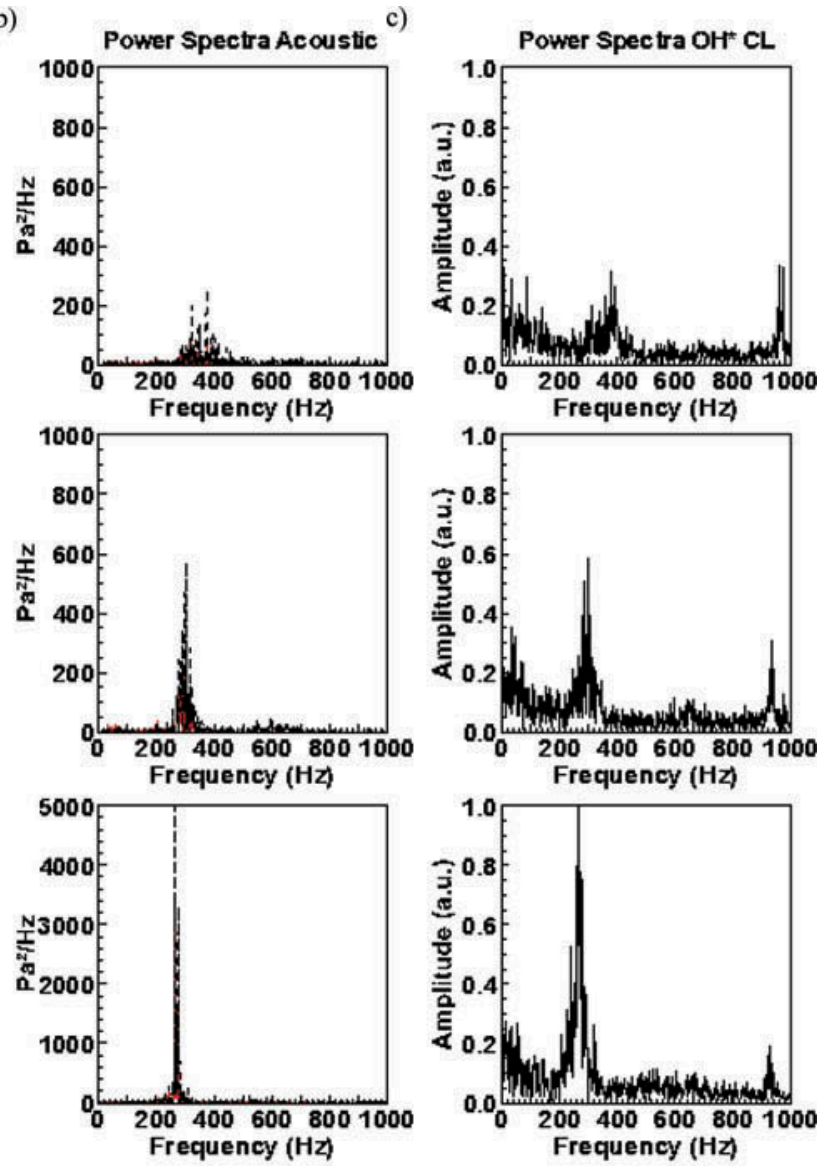

Figure 3 (a) Mean fields of $\mathrm{OH}^{*} \mathrm{CL}$, power spectra of the (b) acoustic and (c) integrated chemiluminescence signal of flames with three different staging ratios 3.3 (Flame 40/60), 1.8 (Flame 55/45), and 1.2 (Flame 65/35), respectively. 
plane for Flame $65 / 35\left(\Phi_{\mathrm{IS}} / \Phi_{\mathrm{OS}}=1.2\right)$. The variation in fuel staging influences the flame zone width as shown in Figure $3 \mathrm{a}$; the $\mathrm{OH}^{*}$ intensity field broadens as the stoichiometry of the air/fuel mixture in the inner swirler stage is reduced.

A slight asymmetry has been observed in the $\mathrm{OH}$ distribution in Flames 40/60 and $55 / 45$. This could be due to radiation from the combustion chamber post passing through the $\mathrm{OH}$ filter, since the $\mathrm{OH}$ PLIF camera system was used for $\mathrm{OH}^{*} \mathrm{CL}$ imaging during the characterization experiments. The $\mathrm{OH}$ filter used in the LIF setup allows transmission of light in the red region. This does not affect the LIF signal because of the shot intensifier gate opening time (500 ns), but may have significant effect for CL measurement due to larger intensifier gate width. It should also be noted that for Flames $40 / 60$ and 55/45, the mixture originating in the inner swirler stage drives the combustion process because $\Phi_{\mathrm{OS}}$ is still below the flammability limit. Any non-uniformity in the mixture originating from the outer swirler stage could also lead to an asymmetric flame.

The acoustic signal was recorded simultaneously with the trigger pulse from the $\mathrm{OH}^{*}$ $\mathrm{CL}$ intensifier. The raw signals from all five probes were calibrated, and power spectra were calculated. Figure $3 \mathrm{~b}$ shows the power spectra of the pressure fluctuation in the combustion chamber measured with the microphone probe labeled "Chamber P2" in Figure 1a. In Flame 40/60, no distinct self-excited acoustic is detected. The first distinct peak in the acoustics measurement is detected in Flame 55/45 at $303 \mathrm{~Hz}$. The acoustic pulsation increases by a factor of eight in Flame 65/35, and the peak is centered at $267 \mathrm{~Hz}$. Power spectra from the integrated $\mathrm{OH}$ signal have been plotted in Figure $3 \mathrm{c}$ for the three corresponding staging ratios. It should be noted that the integrated signal is from half of the $\mathrm{OH}^{*}$ CL image $(x=0-38 \mathrm{~mm})$. The reason for using one-half of the $\mathrm{OH}$ image was to resolve any other periodic feature that may affect the global heat release. The integrated intensity has been normalized by the maximum intensity from Flame $65 / 35$. For frequency range below $500 \mathrm{~Hz}$, no distinct peak in the integrated intensity spectra is detected in Flame $40 / 60$, which corresponds well with the acoustic spectra. Flames 55/45 and 65/35 on the other hand show strong peaks at $298 \mathrm{~Hz}$ and $265 \mathrm{~Hz}$, which is consistent with the dominant thermo-acoustic oscillation. In all the flames, a second peak was detected in the $\mathrm{OH}^{*}$ signal in the frequency range $932-959 \mathrm{~Hz}$. This frequency could be due to the existence of periodic flow structure but requires further detailed analysis of the flow field, and hence will be investigated in a later study. The trends presented in Figure 3 are similar to what Boxx et al. (2012) have reported in investigation of flames with and without strong thermo-acoustic pulsations.

\section{Phase Resolved Analysis}

Phase averaged $\mathrm{OH}$ images measured during flame characterization phase are presented in Figure 4 for Flames 40/60, 55/45, and 65/35, respectively. For each flame, $5000 \mathrm{OH}^{*} \mathrm{CL}$ images were recorded, and for each phase angle, approximately 625 single exposures were used for the mean image. The $\mathrm{OH}^{*} \mathrm{CL}$ intensity to a certain extent is a good marker of the heat release rate and hence its spatial distribution has been used as an indicator of the flame zone (Hardalupas and Orain, 2004). The images in Figure 4 show a comparison of heat release fields from flames with no thermo-acoustic pulsations (Flame 40/60) to a flame where the onset of self-excited thermo-acoustics has started (Flame 55/45) and to Flame 65/35 with strong thermo-acoustic pulsations. No discernible change in the $\mathrm{OH}$ intensity is observed in Flame 40/60 for all phase angles. For Flame 55/45, the $\mathrm{OH}^{*} \mathrm{CL}$ intensity is maximum at phase angle of $90^{\circ}$ and reaches a minimum at $270^{\circ}$. 

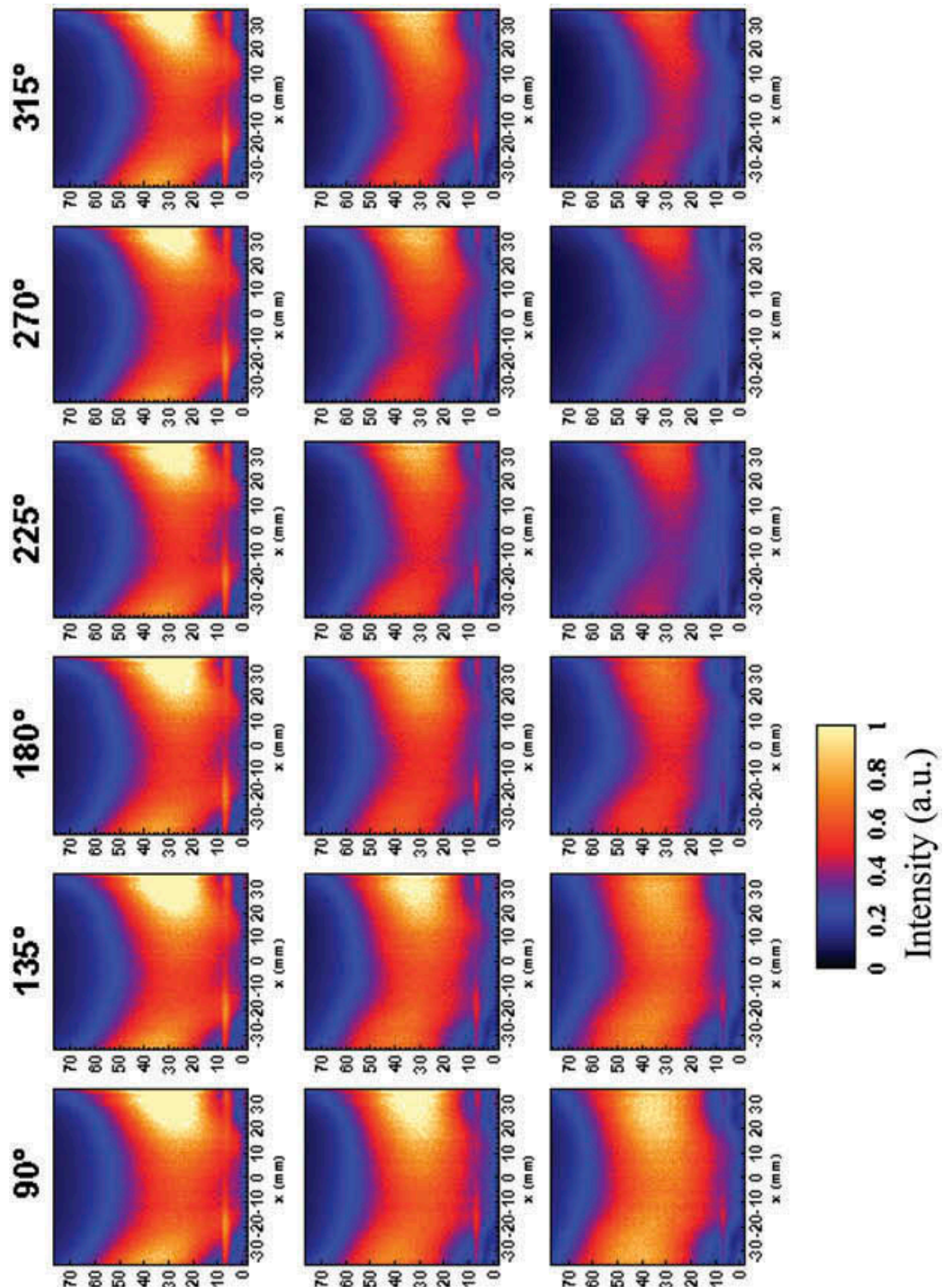

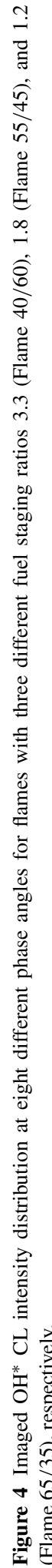
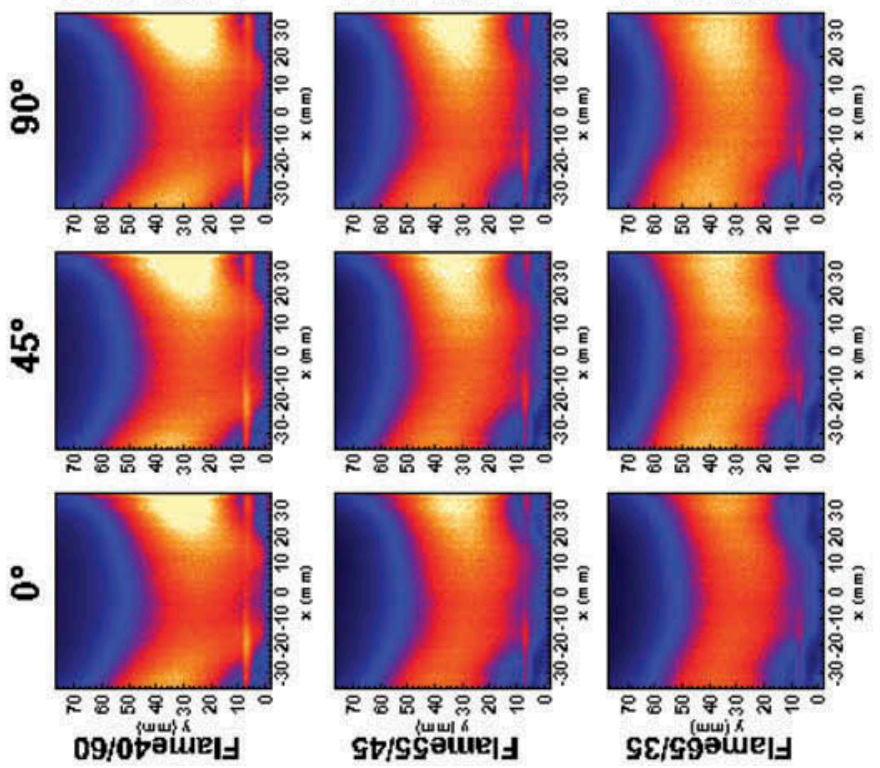

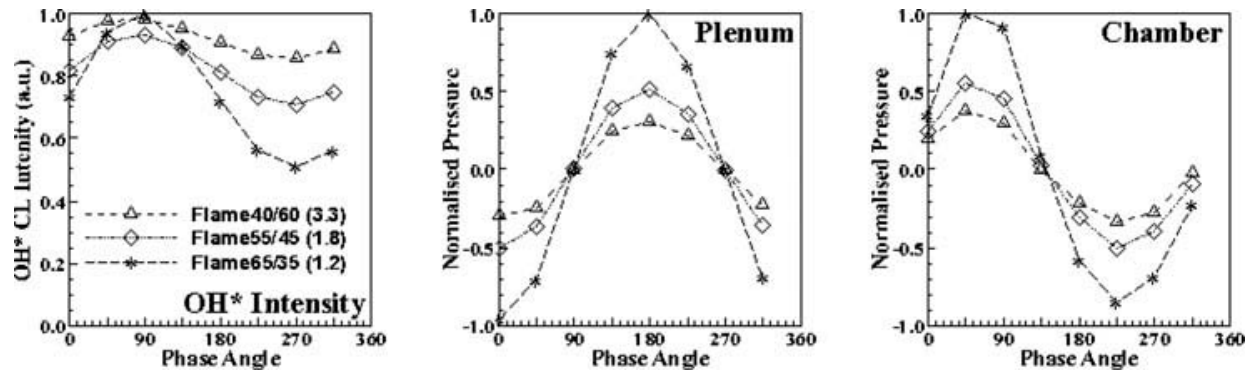

Figure 5 Comparison of normalized $\mathrm{OH}^{*} \mathrm{CL}$ intensity, with normalized pressure in the plenum and combustion chamber for flames with three different fuel staging ratios 3.3 (Flame 40/60), 1.8 (Flame 55/45), and 1.2 (Flame 65/35), respectively.

A similar pattern is observed in Flame 65/35 with a more prominent change in $\mathrm{OH}$ intensity. In all the images Flame 40/60 have a distinct $V$ shape with a narrow heat release zone, whereas Flames 55/45 and 65/35 have a W flame shape with broader heat release zone. This change in flame shape could be due to the acoustic pulsations, which may be the result of the decrease in staging ratio caused by an increase in the equivalence ratio of the air fuel mixture from the outer swirler stage.

Normalized integrated $\mathrm{OH}^{*} \mathrm{CL}$ intensity and pressure in the plenum and combustion chamber are displayed as a function of phase angle in Figure 5 for the three flames. Each profile has been normalized by the maximum of the specific parameter in Flame 65/35. The maximum heat release is measured at $90^{\circ}$ phase angle and the minimum heat release is measured at $270^{\circ}$. The pressure in the plenum has been used to define the phase angles earlier where the minimum pressure is at $0^{\circ}$ for all flames. The maximum and minimum pressure in the combustion chamber occurs at $45^{\circ}$ and $225^{\circ}$, respectively. Thermal expansion due to heat release would cause the pressure in the chamber to increase and thus reduces the injection of fresh charge into the chamber. As the flame cools, the pressure in the chamber reduces, allowing the fresh charge to enter the chamber and mix with the hot exhausts from the inner recirculation zone and the next cycle begins. This important trend is shown in Figure 5, which is during an oscillation cycle. The variations of the heat release rate and the pressure in the combustion chamber are almost in phase. This behavior has been observed by Meier et al. (2007, 2010), as well as Stöhr et al. (2009) in flames of a dual swirl burner that exhibited strong thermo-acoustic oscillations.

One of the major factors that could be influencing the excitation of thermo-acoustic oscillation is the local equivalence ratio of the air fuel mixture. Flame 40/60, which has a staging ratio of 3.3, has a rich air/fuel mixture exciting the inner swirler stage, as shown in Table 1, and is diluted by the very lean fuel air mixture from the outer swirler stage. As the staging ratio decreases to 1.8 in Flame 55/45, which results in mixtures from both stages having equivalence ratio below stoichiometric, the initial self-excited thermo-acoustic frequency is detected as shown in Figure 3b. Further reduction of the staging ratio to 1.2 in Flame 65/35 leads to significant increase in the thermo-acoustic pulsation. The variation in equivalence ratio resulting from staging seems to initiate the pulsation in heat release and pressure in the combustion chamber.

This effect is further investigated by using OH PLIF imaging performed in the three flames investigated. Figure 6 shows instantaneous OH PLIF images at four random phase angles from one acoustic cycle in Flame 40/60 and Flame 65/35. There is no correlation 

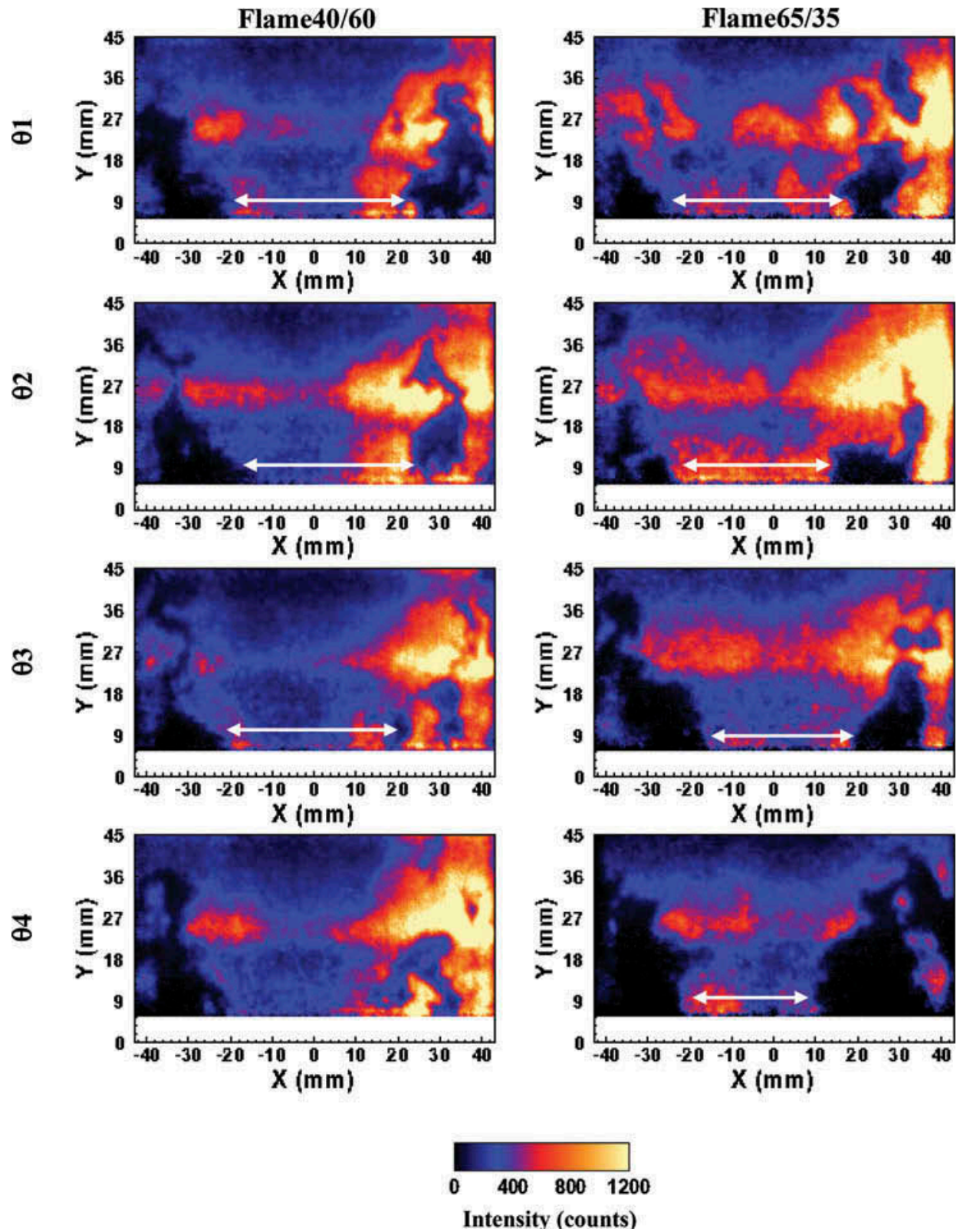

Figure 6 Instantaneous OH PLIF images at four phase angles $(\theta 1, \ldots \theta 4)$ for one acoustic cycle in Flame $40 / 60$ and Flame $65 / 35$ with staging ratio 3.3 (without thermo-acoustics) and 1.2 (with strong thermo-acoustics), respectively.

between the time sequences of the two flames. The image at $\theta 1$ has been randomly chosen, followed by successive images at three other phase angles for one acoustic cycle. The size of single OH PLIF image is $45 \times 85 \mathrm{~mm}$. The flow direction in all images is from bottom to top. All images have been corrected for background noise and normalized by mean image of the laser beam profile. The asymmetry observed in the images is due to laser absorption, 
which has not been corrected for. The corresponding OH PLIF images show regions without $\mathrm{OH}$ (black) representing unburned gas that exits the burner. The high intensity areas represented by orange to white regions are the super-equilibrium concentrations of $\mathrm{OH}$ formed in the reaction zones that decay toward equilibrium levels over several milliseconds (Sadanandan et al., 2008). Medium and low levels of OH (blue to red) represent burned gas whose $\mathrm{OH}$ concentration has decayed toward equilibrium, while it was transported away from the reaction zone.

The fresh fuel/air mixture penetrating into the hot zone is small and narrow as marked by the black zones in Flame 40/60. It should be noted that the flame base in Flame $40 / 60$ is upstream of the burner exit plane. The existence of super equilibrium $\mathrm{OH}$ in Flame 40/60 for the whole cycle remains close to the combustor walls, and the central section contains equilibrium $\mathrm{OH}$ representing recirculated burned gas. This central zone indicates that Flame 40/60 has a broad inner recirculation zone. Flame 65/35 on the other hand shows wider and longer penetration of fresh air/fuel mixture surrounded by varying sizes of high-concentration $\mathrm{OH}$ field, indicating hot reaction zones. The reaction zones exist both in the inner as well as outer shear layer. The areas representing fresh fuel air mixture in Flame 65/35 contract and expand axially as well as radially. This results in the opposite effect on the inner recirculation zone where a broad zone of fresh fuel/air mixture results in a narrow burned gas region in the middle of the image as observed at $\theta 3$ and $\theta 4$. The OH PLIF images show that in Flame 40/60, no change is observed in the width of the inner recirculation zone, whereas Flame 65/35, which has strong thermo-acoustics, shows a strong variation in the shape of the inner recirculation zone. The modulation of the inner recirculation zone in Flame 65/35 could be due to two streams of mixture (outer and inner stage) with equivalent stoichiometry $\left(\Phi_{\mathrm{IS}} / \Phi_{\mathrm{OS}}=1.1\right)$ competing to stabilize the flame.

\section{SUMMARY AND CONCLUSIONS}

The effect of fuel staging on the behavior of a lean premixed swirl flame has been investigated using $\mathrm{kHz} \mathrm{OH} \mathrm{PLIF}, \mathrm{OH}^{*} \mathrm{CL}$, and acoustic measurement techniques. A model gas turbine burner with two coaxially mounted swirlers having individual fuel feed lines is used for fuel staging. The staging is varied by reducing the percentage of fuel in the inner swirler and increasing it in the outer swirler. The maximum amount of fuel in the outer swirler was $65 \%$, and beyond this amount of fuel, resulted in strong thermo-acoustics, which caused optical combustion chamber windows to break.

Altogether stable operations were achieved for six staging ratios. In the flame with staging ratio of 1.8 , the initial acoustic peak is detected at $303 \mathrm{~Hz}$ in the power spectra measured using the microphone probes. All flames with higher than $45 \%$ fuel injection in the inner swirler have no thermo-acoustics, and as the fuel is further reduced from $45 \%$, the strength of the thermo-acoustic pulsations increases significantly and peaks at $267 \mathrm{~Hz}$. The flame shape changes from a $\mathrm{V}$-shaped flame with a narrow reaction zone to a $\mathrm{W}$-shape with a broader reaction zone. Using $\mathrm{OH}^{*}$ as a marker of the heat release zones, the phase resolved analysis shows that flame with staging ratio 3.3 (no thermo-acoustic) has no discernible change in the heat release. As the self-excited thermo-acoustic is initiated in flame with staging ratio 1.8 , the $\mathrm{OH}^{*} \mathrm{CL}$ images show heat release reaching a maximum at a phase angle of $90^{\circ}$ and then reducing to a minimum at $270^{\circ}$. This pulsation is more prominent in flame with staging ratio 1.2. The pressure oscillation measured in the combustion chamber is in phase with the heat release rate. 
In this study, all the initial conditions were kept constant while varying the fuel staging. Fuel is injected at the base of the swirlers, which allows for some premixing to occur before the streams from the inner and outer swirler interact. Even though the global equivalence ratio $\left(\Phi_{\mathrm{G}}\right)$ is constant, the equivalence ratio of the mixture from inner swirler stage starts rich and reduces to $\Phi_{\mathrm{G}}$ as the staging ratio is varied. This variation in the mixture stoichiometry from each swirler stage has a strong influence on the flame stabilization mechanism. In flame with staging ratio 1.2 (Flame 65/35), the mixtures from both swirler stages seem to be competing to stabilize the flame and hence lead to the strong acoustic pulsations.

Future work in this series of studies will be to investigate flames with strong thermoacoustics, as was in the case with staging ratio 1.2, and to study the effect of $\Phi_{\mathrm{G}}$ variation at a fixed staging ratio.

\section{FUNDING}

The work presented here has been carried out as part of the BIGH2 Phase II project, which is funded by Gassnova, the German Federal Ministry of Economics and Technology (03ET2008), and Alstom (Switzerland) Ltd. The authors would like to thank the project partners SINTEF Energi AS and Alstom (Switzerland) Ltd for their contribution. The authors take the responsibility for the content of the article.

\section{REFERENCES}

Adachi, S., Iwamoto, A., Hayashi, S., Yamada, H., and Kaneko, S. 2007. Emissions in combustion of lean methane-air and biomass-air mixtures supported by primary hot burned gas in a multi-stage gas turbine combustor. Proc. Combust. Inst., 31, 3131-3138.

Barbosa, S., Scouflaire, P., and Ducruix, S. 2009. Time resolved flowfield, flame structure and acoustic characterisation of a staged multi-injection burner. Proc. Combust. Inst., 32, 2965-2972.

Boxx, I., Arndt, C., Carter, C., and Meier, W. 2012. High-speed laser diagnostics for the study of flame dynamics in a lean premixed gas turbine model combustor. Exp. Fluids, 52, 555-567.

Boxx, I., Stöhr, M., Carter, C., and Meier, W. 2010. Temporally resolved planar measurements of transient phenomena in a partially pre-mixed swirl flame in a gas turbine model combustor. Combust. Flame, 157, 1510-1525.

Chockalingam, P., Galeazzo, F.C.C., Kasabov, P., Habisreuther, P., Zarzalis, N., Beck, C., Krebs, W., and Wegner, B. 2011. Analysis of NOX formation in an axially staged combustion system at elevated pressure conditions. In Proceedings of the ASME Turbo Expo, Vancouver, British Columbia, Canada, May 8-11. ASME, New York, GT2011-45239.

Duan, X.R., Meier, W., Weigand, P., and Lehmann, B. 2005. Phase-resolved laser Raman scattering and laser Doppler velocimetry applied to periodic instabilities in a gas turbine model combustor. Appl. Phys. B, 80, 389-396.

Fritsche, D., Füri, M., and Boulouchos, K. 2007. An experimental investigation of thermoacoustic instabilities in a premixed swirl-stabilized flame. Combust. Flame, 151, 29-36.

Geigle, K.P., Meier, W., Aigner, M., Willert, C., Jarius, M., Schmitt, P., and Schuermans, B. 2006. Phase resolved laser diagnostic measurements of a downscaled, fuel staged gas turbine combustor at elevated pressure and comparison with LES predictions. In Proceedings of the ASME Turbo Expo, Barcelona, Spain, May 8-11. ASME, New York, GT2006-90875.

Giezendanner, R., Keck, O., Weigand, P., Meier, W., Meier, U., Stricker, W., and Aigner, M. 2003. Periodic combustion instabilities in a swirl burner studied by phase-locked planar laser-induced fluorescence. Combust. Sci. Technol., 175, 721-741. 
Gounder, J.D., Boxx, I., Kutne, P., Biagioli, F., and Luebcke, H. 2013. An investigation of the effects of fuel staging on flame structure in a gas turbine model combustor. In Proceedings of the ASME Turbo Expo, San Antonio, TX, June 3-7. ASME, New York, GT2013-95520.

Grinstein, F.F., and Fureby, C. 2005. LES studies of the flow in a swirl gas combustor. Proc. Combust. Inst., 30, 1791-1798.

Haber, L.C., and Vandsburger, U. 2003. A global reaction model for $\mathrm{OH}^{*}$ chemiluminescence applied to a laminar flat-flame burner. Combust. Sci. Technol., 175, 1859-1891.

Hardalupas, Y., and Orain, M. 2004. Local measurements of the time-dependent heat release rate and equivalence ratio using chemiluminescent emission from a flame. Combust. Flame, 139, 188-207.

Hayashi, S., Yamada, H., and Makida, M. 2005. Extending low-NOx operating range of a lean premixed-prevaporized gas turbine combustor by reaction of secondary mixtures injected into primary stage burned gas. Proc. Combust. Inst., 30, 2903-2911.

Johnson, M.R., Littlejohn, D., Nazeer, W.A., Smith, K.O., and Cheng, R.K. 2005. A comparison of the flowfields and emissions of high-swirl injectors and low-swirl injectors for lean premixed gas turbines. Proc. Combust. Inst., 30, 2867-2874.

Jones, W.P., Marquis, A.J., and Prasad, V.N. 2012. LES of a turbulent premixed swirl burner using the Eulerian stochastic field method. Combust. Flame, 159, 3079-3095.

Kolb, T., Jansohn, P., and Leuckel, W. 1988. Reduction of NO, emission in turbulent combustion by fuel-staging/effects of mixing and stoichiometry in the reduction zone. Proc. Combust. Inst., 22, $1193-1203$.

Lefebvre, A.H., and Ballal, D.R. 2010. Gas Turbine Combustion: Alternative Fuels and Emissions, 3rd ed., CRC Press, Boca Raton, FL.

Littlejohn, D., and Cheng, R.K. 2007. Fuel effects on a low-swirl injector for lean premixed gas turbines. Proc. Combust. Inst., 31, 3155-3162.

Martin, C.E., Benoit, L., Sommerer, T., Nicoud, F., and Poinsot, T. 2006. Large-eddy simulation and acoustic analysis of a swirled staged turbulent combustor. AIAA J., 44, 741-749.

Meier, W., Boxx, I., Stöhr, M., and Carter, C. D. 2010. Laser-based investigations in gas turbine model combustors. Exp. Fluids, 49, 865-882.

Meier, W., Weigand, P., Duan, X.R., and Giezendanner-Thoben, R. 2007. Detailed characterization of the dynamics of thermoacoustic pulsations in a lean premixed swirl flame. Combust. Flame, 150, 2-26.

Moeck, J.P., Bourgouin, J.-F., Durox, D., Schuller, T., and Candel, S. 2012. Nonlinear interaction between a precessing vortex core and acoustic oscillations in a turbulent swirling flame. Combust. Flame, 159, 2650-2668.

Nogenmyr, K.J., Fureby, C., Bai, X.S., Petersson, P., Collin, R., and Linne, M. 2009. Large eddy simulation and laser diagnostic studies on a low swirl stratified premixed flame. Combust. Flame, 156, 25-36.

Sadanandan, R., Stöhr, M., and Meier, W. 2008. Simultaneous OH-PLIF and PIV measurements in a gas turbine model combustor. Appl. Phys. B, 90, 609-618.

Sadanandan, R., Stöhr, M., and Meier, W. 2009. Flowfield-flame structure interactions in an oscillating swirl flame. Combust. Explos. Shock Waves, 45, 518-529.

Stöhr, M., Boxx, I., Carter, C., and Meier, W. 2011a. Dynamics of lean blowout of a swirl-stabilized flame in a gas turbine model combustor. Proc. Combust. Inst., 33, 2953-2960.

Stöhr, M., Boxx, I., Carter, C.D., and Meier, W. 2012. Experimental study of vortex-flame interaction in a gas turbine model combustor. Combust. Flame, 159, 2636-2649.

Stöhr, M., Sadanandan, R., and Meier, W. 2009. Experimental study of unsteady flame structures of an oscillating swirl flame in a gas turbine model combustor. Proc. Combust. Inst., 32, 2925-2932.

Stöhr, M., Sadanandan, R., and Meier, W. 2011b. Phase-resolved characterization of vortex-flame interaction in a turbulent swirl flame. Exp. Fluids, 51, 1153-1167.

Steinberg, A.M., Boxx, I., Stöhr, M., Carter, C.D., and Meier, W. 2010. Flow-flame interactions causing acoustically coupled heat release fluctuations in a thermo-acoustically unstable gas turbine model combustor. Combust. Flame, 157, 2250-2266. 
Therkelsen, P.L., Portillo, J.E., Littlejohn, D., Martin, S.M., and Cheng, R.K. 2013. Self-induced unstable behaviors of $\mathrm{CH}_{4}$ and $\mathrm{H}_{2} / \mathrm{CH}_{4}$ flames in a model combustor with a low-swirl injector. Combust. Flame, 160, 307-321.

Zajadatz, M., Lachner, R., Bernero, S., Motz, C., and Flohr, P. 2007. Development and design of ALSTOM's staged fuel gas injection EV burner for NOx reduction. In Proceedings of the ASME Turbo Expo, Montreal, Canada, May 14-17. ASME, New York, GT2007-27730. 